\title{
Investigation of $\mathrm{Si}$ and $\mathrm{O}$ Donor Impurities in Unintentionally Doped MBE-Grown GaN on SiC(0001) Substrate
}

\author{
TOBIAS TINGBERG, ${ }^{1,2}$ TOMMY IVE, ${ }^{1}$ and ANDERS LARSSON ${ }^{1}$ \\ 1.-Photonics Group, Department of Microtechnology and Nanoscience, Chalmers University of \\ Technology, 41296 Gothenburg, Sweden. 2.—e-mail: tobias.tingberg@gmail.com
}

We have investigated the unintentional $n$-type background doping in $\mathrm{GaN}(0001)$ layers grown on semi-insulating $4 \mathrm{H}-\mathrm{SiC}(0001)$ substrate by plasma-assisted molecular beam epitaxy under Ga-rich conditions at growth temperatures from $780^{\circ} \mathrm{C}$ and $900^{\circ} \mathrm{C}$. All layers exhibited very smooth surface morphology with monolayer steps as revealed by atomic force microscopy. Hall-effect measurements showed that the sample grown at $900^{\circ} \mathrm{C}$ had carrier concentration of $9.8 \times 10^{17} \mathrm{~cm}^{-3}$ while the sample grown at $780^{\circ} \mathrm{C}$ had resistivity too high to obtain reliable measurements. Secondary-ion mass spectroscopy revealed $\mathrm{O}$ and $\mathrm{Si}$ concentrations of $<10^{17} \mathrm{~cm}^{-3}$ in the sample grown at $900^{\circ} \mathrm{C}$ but $>10^{17} \mathrm{~cm}^{-3}$ in the sample grown at $780^{\circ} \mathrm{C}$. The trend for the atomic concentrations of $\mathrm{O}$ and $\mathrm{Si}$, which are common donor impurities in GaN, was thus contrary to the trend of the carrier concentration. The fullwidth at half-maximum for x-ray rocking curves obtained across the $\mathrm{GaN}(0002)$ and $\mathrm{GaN}(10 \overline{15})$ reflections for the sample grown at $900^{\circ} \mathrm{C}$ was 62 arcsec and 587 arcsec, respectively. The half-width increased with decreasing growth temperature. The atomic concentrations of $\mathrm{O}$ and $\mathrm{Si}$ are too low to account for the unintentional background doping levels. A possible explanation proposed in early reports for the background doping is $\mathrm{N}$-vacancies.

Key words: Molecular beam epitaxy, gallium nitride, unintentional doping, Si donor, O donor, N-vacancy

\section{INTRODUCTION}

It is well known that GaN exhibits unintentional $n$-type background doping. In epitaxial GaN layers, this $n$-doping concentration is typically between mid $10^{16} \mathrm{~cm}^{-3}$ and high $10^{17} \mathrm{~cm}^{-3}$. Various explanations have been proposed for such unintentional $n$ type doping. Early reports attributed the unintentional doping to $\mathrm{N}$-vacancies. In later reports, it was suggested that impurities such as $\mathrm{Si}$ and $\mathrm{O}$ were the cause of the inherent $n$-type background, and this explanation remains predominant today. ${ }^{1-4}$

Important devices including light-emitting diodes, laser diodes, and transistors rely on doping of semiconductors. High doping concentrations of both $n$-type and $p$-type layers are critical for many

(Received July 20, 2016; accepted March 28, 2017;

published online April 6, 2017) such devices. Regarding GaN, $p$-type doping is an especially challenging task. To achieve desired levels of $p$-doping, care has to be taken to control the $n$-type background to minimize its compensating effects. ${ }^{5-7}$

Today, GaN grown using metalorganic chemical vapor deposition (MOCVD) is typically applied for optoelectronic devices, due to its better electronic and optical properties. However, when using the Ga-rich growth window, molecular beam epitaxygrown GaN has shown promising results. ${ }^{8-10}$

In this work, we studied the impact of $\mathrm{Si}$ and $\mathrm{O}$ impurities on the unintentional $n$-type background doping concentration in GaN layers grown under Ga-rich conditions by plasma-assisted molecular beam epitaxy (MBE). Semi-insulating $\mathrm{SiC}$ substrates were used for all samples. Compared with sapphire, which is often used for epitaxially grown 
$\mathrm{GaN}, \mathrm{SiC}$ has the advantage of lower crystalline mismatch, and has been known to yield high-quality GaN epilayers for over a decade. ${ }^{11-14}$

Hall-effect measurements were performed to measure the background doping in each sample. Secondary-ion mass spectroscopy (SIMS) was used to measure the levels of $\mathrm{Si}$ and $\mathrm{O}$ in the epilayers. Our results suggest that the studied impurities cannot be the cause of the unintentional $n$-type doping in our GaN layers.

\section{EXPERIMENTAL PROCEDURES}

The samples were grown in a Varian Mod GEN-II MBE system equipped with solid-source effusion cells for evaporation of Ga with purity of $7 \mathrm{~N}$ and an SVTA 4.5 radiofrequency (RF) plasma source for provision of active $\mathrm{N}$. We used $7 \mathrm{~N} \mathrm{~N}_{2}$ gas as precursor for the plasma source.

A reflectance high-energy electron diffraction (RHEED) system attached to the MBE growth chamber was used to monitor the growth front. The growth chamber had base pressure of $4 \times 10^{-11} \mathrm{kPa}$. All samples were rotated continuously during the growth experiments.

Semi-insulating $76.2-\mathrm{mm} \quad 4 \mathrm{H}-\mathrm{SiC}(0001)$ wafers purchased from Cree, Inc. were used as substrates. The $4 \mathrm{H}-\mathrm{SiC}$ wafers were postpolished by NovaSiC and had resistivity $\rho \geq 10^{5} \Omega \mathrm{cm}$. All wafers were cleaved into $1 \mathrm{~cm} \times 1 \mathrm{~cm}$ pieces and sonicated in acetone, isopropanol, and deionized water before being mounted with In on the substrate holder. An in situ Ga-polishing or Ga flash-off procedure was performed on the $\mathrm{SiC}$ substrates prior to $\mathrm{GaN}$ growth to remove suboxides residing on the $\mathrm{SiC}$ substrate surface. ${ }^{15}$ The bare SiC substrate surface yielded a $1 \times 1$ RHEED pattern prior to the Ga flash-off procedure. An abrupt transition from this $1 \times 1$ RHEED pattern to a distinct $3 \times 1$ pattern was observed once the surface was free of suboxides. This characteristic $3 \times 1$ RHEED pattern occurs at $720^{\circ} \mathrm{C}$ and corresponds to Si-induced surface reconstruction. ${ }^{16}$ This transition was used as an independent in situ temperature calibration of the substrate temperature before each growth experiment.

All samples were grown under Ga-rich conditions. It is well known that this growth condition yields very smooth surface morphology but also residual $1-\mu \mathrm{m}$ - to $2-\mu \mathrm{m}$-wide $\mathrm{Ga}$ droplets on the sample surface. ${ }^{17-19}$ The droplets were removed by etching each sample in $\mathrm{HCl}: \mathrm{H}_{2} \mathrm{O}$ (1:3). Optical microscopy was used to verify that the droplets had been removed.

$\mathrm{N}$-plasma $\mathrm{RF}$ power of $400 \mathrm{~W}$ and $\mathrm{N}_{2}$ flow rate of 3 standard cubic centimeters per minute $(\mathrm{sccm})$ were used for all growth experiments.

The structural quality of the samples was assessed by x-ray diffraction (XRD) analysis using a PANalytical X'Pert PRO MRD four-circle tripleaxis diffractometer equipped with a $\mathrm{Cu} \mathrm{K}_{\alpha}$ source at the focus of a $\mathrm{Ge}(220)$ hybrid monochromator.
The mosaicity (tilt and twist) of the layers was examined by recording $\mathrm{x}$-ray rocking curves (XRCs) across the on-axis symmetric (0002) and across the (1015) reflection (in skew-symmetric geometry), respectively.

The surface morphology was examined using a Bruker Dimension 3100 atomic force microscope (AFM) operated in tapping mode with a Si cantilever.

The GaN/SiC samples were cleaved after growth, and the thickness of each layer was measured from cross-sectional scanning electron microscopy (SEM) images of the cleaved sample edge, obtained using a Zeiss Ultra 55 FEG SEM.

We used a Biorad Hall-effect measurement setup to characterize the samples electrically. Ohmic contacts in van der Pauw geometry were deposited by e-beam evaporation, consisting of $20 \mathrm{~nm} \mathrm{Ni}$ followed by $60 \mathrm{~nm} \mathrm{Au}$.

Elemental analysis of the samples was done by secondary-ion mass spectroscopy (SIMS) by Evans Analytical Group.

\section{RESULTS}

Selected properties and growth conditions for the samples are presented in Table I.

Figure 1 shows AFM micrographs obtained from the surface of samples A and B. Sample A (grown at $900^{\circ} \mathrm{C}$ ) exhibited step-flow growth morphology, whereas sample B (grown at $860^{\circ} \mathrm{C}$ ) showed surface morphology associated with a spiral growth mode resulting in hexagonal hillocks. ${ }^{20-24}$ The surface morphology of samples $\mathrm{C}$ and $\mathrm{D}$ was similar to that of sample $B$, but the density of spiral hillocks on the surface increased when $T_{\mathrm{G}}$ was lowered.

All samples showed very smooth surface morphology with observable monolayer steps and rootmean-square (RMS) roughness $<1.2 \mathrm{~nm}$.

Figure 2 shows the full-width at half-maximum (FWHM) of XRCs recorded across the (0002) and (1015) reflections as a function of growth temperature $T_{\mathrm{G}}$ for the GaN/SiC layers.

We found that the XRC FWHM for both reflections decreased with increasing $T_{\mathrm{G}}$. The narrowest peak widths were measured for sample A, which was grown at $T_{\mathrm{G}}=900^{\circ} \mathrm{C}$. The FWHM of the XRC peak for the (0002) reflection was 62 arcsec for this sample. This XRC scan is sensitive to the tilt mosaic, which is correlated to the screw dislocation density in the layer. The corresponding value for the (1015) reflection was 587 arcsec. The off-axis value is a measure of the twist mosaic, which is sensitive to the density of edge dislocations.

The density of screw- and edge-type threading dislocations (TDs) can be estimated using the expressions in Ref. 25. We estimated the TD density in sample A to be $1.8 \times 10^{9} \mathrm{~cm}^{-2}$, directly comparable to literature values for GaN grown by MBE. The observed trend is expected since higher $T_{\mathrm{G}}$ yields better structural quality within the growth window. $^{26}$ 
Table I. Summary of selected properties and growth conditions for samples

\begin{tabular}{|c|c|c|c|c|c|}
\hline Sample & $T_{\mathbf{G}}\left({ }^{\circ} \mathbf{C}\right)$ & $d(\mathbf{n m})$ & RMS (nm) & $\Delta \omega(0002)(\operatorname{arcsec})$ & $\Delta \omega(10 \overline{15})($ arcsec $)$ \\
\hline $\mathrm{A}$ & 900 & 496 & 0.059 & 62 & 587 \\
\hline B & 860 & 463 & 0.574 & 85 & 727 \\
\hline $\mathrm{C}$ & 820 & 478 & 1.19 & 119 & 814 \\
\hline $\mathrm{D}$ & 780 & 302 & 0.38 & 220 & 1010 \\
\hline
\end{tabular}

$T_{\mathrm{G}}$, growth temperature; $d$, layer thickness; RMS, root-mean-square roughness obtained from AFM scans over $2 \mu \mathrm{m} \times 2 \mu \mathrm{m}$ area; $\Delta \omega(0002)$ and $\Delta \omega(10 \overline{15})$, full-width at half-maximum of x-ray rocking curves.
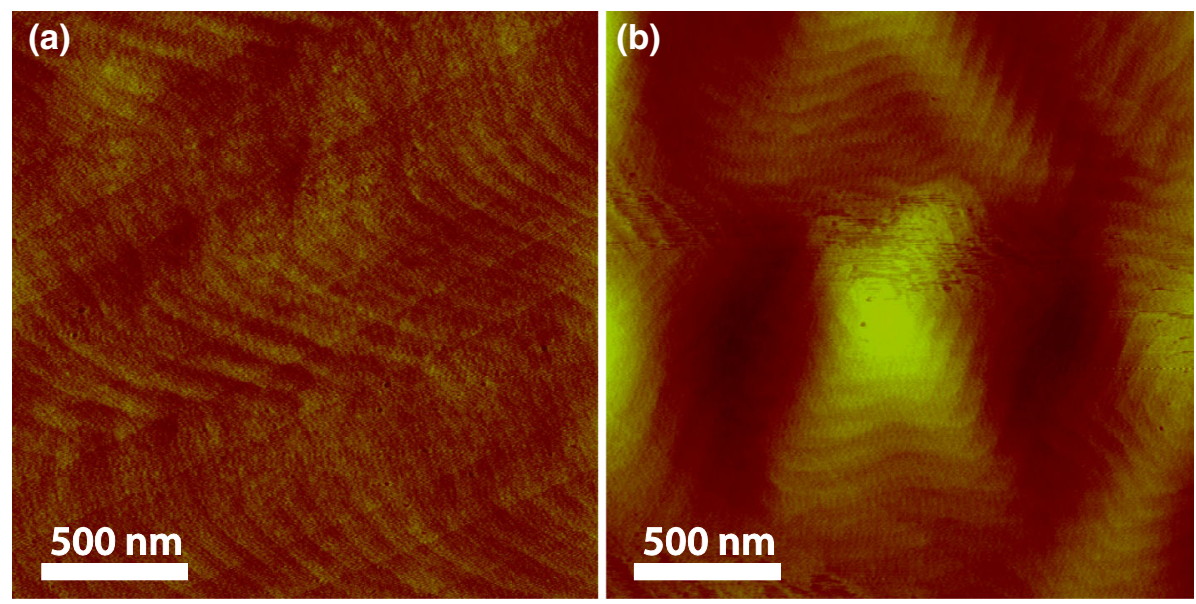

Fig. 1. AFM micrographs of samples grown at (a) $900^{\circ} \mathrm{C}$ (sample A) and (b) $860^{\circ} \mathrm{C}$ (sample B).

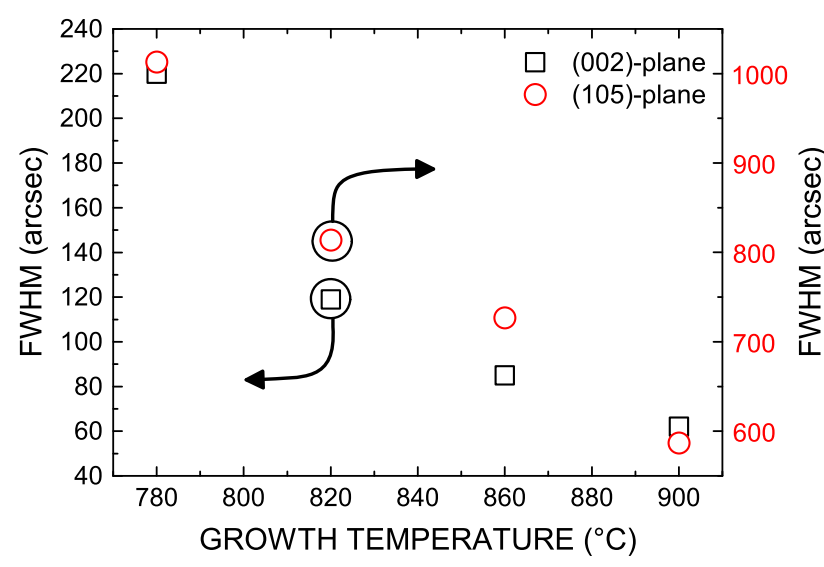

Fig. 2. (color online) Peak widths of XRD rocking curves for (0002) and (1015) reflections as function of $\mathrm{GaN} / \mathrm{SiC}$ growth temperature.

The $n$-type charge carrier concentration and mobility were assessed by Hall-effect measurements for samples $\mathrm{A}$ to $\mathrm{C}$ and are shown in Fig. 3 as functions of $T_{\mathrm{G}}$.

The $n$-type background is the result of unintentional doping of the layers, and it was observed that the charge carrier concentration decreased with a reduction of $T_{\mathrm{G}}$. The electron mobility showed a similar pattern. The decrease in electron mobility

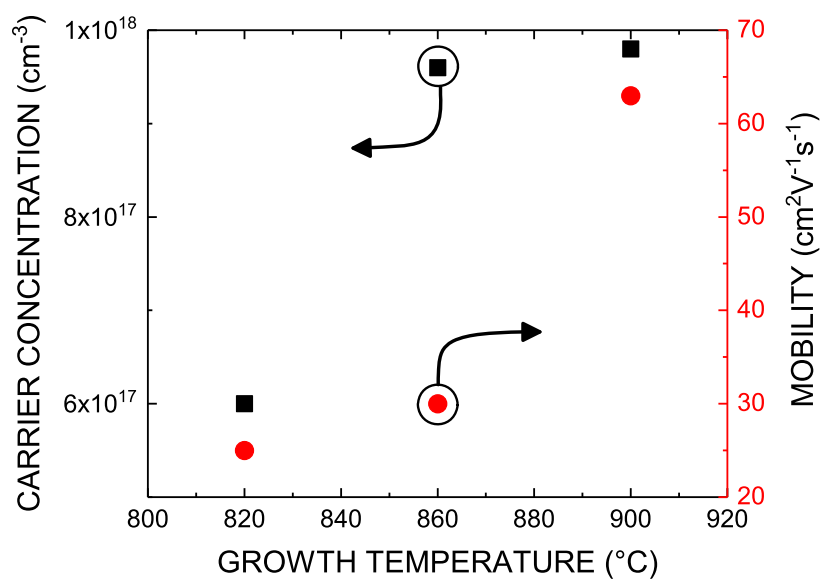

Fig. 3. (color online) Carrier concentration and mobility as functions of GaN growth temperature (samples A to C).

with decreasing $T_{\mathrm{G}}$ is in agreement with mobility being dominated by dislocation and impurity scattering events. Compensating effects in GaN due to high carrier concentrations are expected in the range of $10^{18} \mathrm{~cm}^{-3}$ to $10^{19} \mathrm{~cm}^{-3} \cdot 27-30$

It was not possible to measure the carrier concentration in sample $\mathrm{D}\left(T_{\mathrm{G}}=780^{\circ} \mathrm{C}\right)$, since the resistivity of this sample was very high. Sample A 


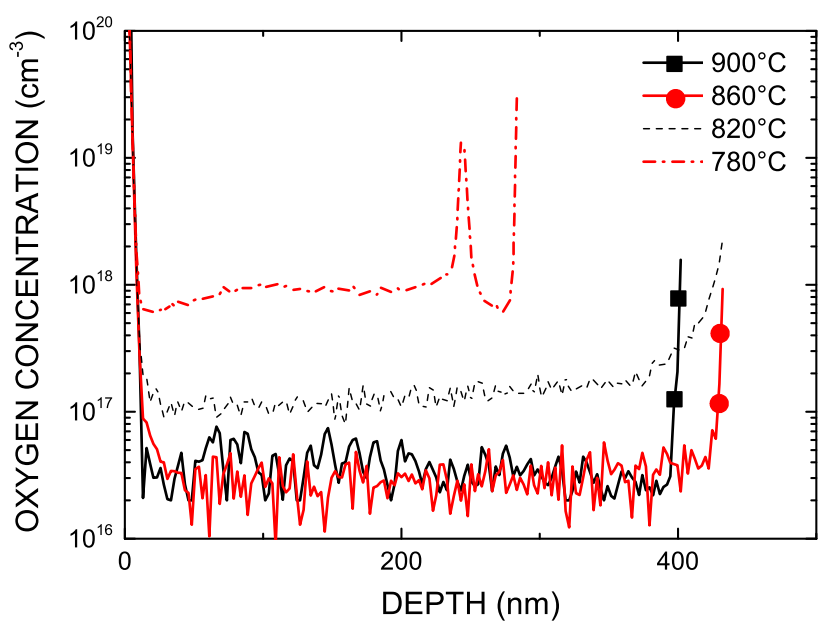

Fig. 4. SIMS depth profile of $O$ concentration in GaN/SiC layers grown at different growth temperatures. The sharp increase of the $\mathrm{O}$ concentration indicates the $\mathrm{GaN} / \mathrm{SiC}$ interface. Note that the sample thickness is different for the sample grown at $780^{\circ} \mathrm{C}$. The $\mathrm{O}$ peak close to the $\mathrm{GaN} / \mathrm{SiC}$ interface for the sample grown at $780^{\circ} \mathrm{C}$ was attributed to a growth interruption.

$\left(T_{\mathrm{G}}=900^{\circ} \mathrm{C}\right)$, which exhibited both the smoothest surface morphology and the highest structural quality, also had the highest unintentional background doping concentration $\left(n=9.8 \times 10^{17} \mathrm{~cm}^{-3}\right)$ and the highest mobility $\left(\mu=63 \mathrm{~cm}^{2} \mathrm{~V}^{-1} \mathrm{~s}^{-1}\right)$.

Figure 4 shows the atomic $\mathrm{O}$ concentration for all samples as revealed by SIMS. We observed that the concentration of $\mathrm{O}$ increased with decreasing $T_{\mathrm{G}}$. For samples A and $\mathrm{B},[\mathrm{O}]<5 \times 10^{16} \mathrm{~cm}^{-3}$.

The [O] value was $1 \times 10^{17} \mathrm{~cm}^{-3}$ in sample $\mathrm{C}$ and $<1 \times 10^{18} \mathrm{~cm}^{-3}$ in sample D (excluding the peak close to the interface, which we believe to be due to a growth interruption). In contrast, the charge carrier concentration increased for higher $T_{\mathrm{G}}$. This is unexpected, since previous reports suggest that $\mathrm{O}$ is the cause for the unintentional background doping. ${ }^{31,32}$ High $\mathrm{O}$ concentration should therefore lead to high background concentration, whereas we observed the opposite.

The concentration of $\mathrm{Si}$ atoms in the GaN layers measured by SIMS is shown in Fig. 5. The Si level was $<10^{17} \mathrm{~cm}^{-3}$ throughout all the sample layers, except close to the GaN/SiC interface, where it increased slightly to $1 \times 10^{17} \mathrm{~cm}^{-3}$ to $2 \times 10^{17} \mathrm{~cm}^{-3}$ due to diffusion of $\mathrm{Si}$ from the $\mathrm{SiC}$ into the $\mathrm{GaN}$ layer.

The Si concentration is too low to account for the measured charge carrier concentrations and hence cannot be the cause of the background doping.

\section{DISCUSSION AND CONCLUSIONS}

The carrier concentration increased when the sample growth temperature was increased. The amount of $\mathrm{O}$ decreased with increasing growth temperature. The Si concentration was essentially constant throughout all the sample layers, except close to the $\mathrm{GaN} / \mathrm{SiC}$ interface, where the amount of $\mathrm{Si}$ increased slightly due to outdiffusion of $\mathrm{Si}$

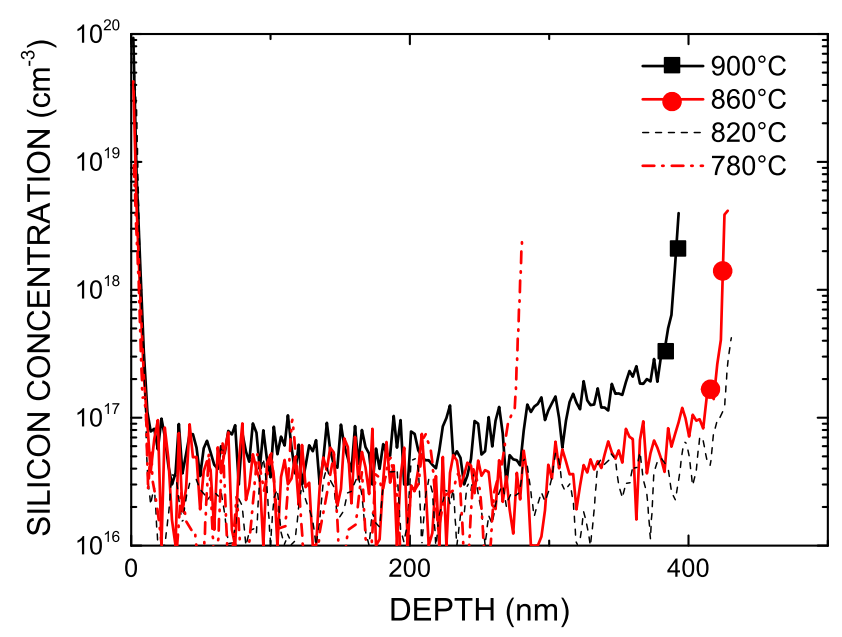

Fig. 5. SIMS depth profile of Si concentration in GaN/SiC layers grown at different growth temperatures. The sharp increase of the $\mathrm{Si}$ concentration indicates the $\mathrm{GaN} / \mathrm{SiC}$ interface. Note that the sample thickness is different for the sample grown at $780^{\circ} \mathrm{C}$. The large $\mathrm{Si}$ content at the GaN surface is an artifact of the SIMS measurement.

from the $\mathrm{SiC}$ substrate. The $\mathrm{O}$ content was $<5 \times 10^{16} \mathrm{~cm}^{-3}$ for the samples grown at $T_{\mathrm{G}}=900^{\circ} \mathrm{C}$ and $860^{\circ} \mathrm{C}$, whereas the $\mathrm{O}$ content was $1 \times 10^{17} \mathrm{~cm}^{-3}$ and $<1 \times 10^{18} \mathrm{~cm}^{-3}$ for the samples grown at $820^{\circ} \mathrm{C}$ and $780^{\circ} \mathrm{C}$, respectively. The $\mathrm{Si}$ content for all samples was approximately $1 \times 10^{17} \mathrm{~cm}^{-3}$. The concentrations of these impurities are too low to be the cause of the background doping, which was between $6 \times 10^{17} \mathrm{~cm}^{-3}$ and $9 \times 10^{17} \mathrm{~cm}^{-3}$. The electron mobility $\mu$ was determined to be $63 \mathrm{~cm}^{2} \mathrm{~V}^{-1} \mathrm{~s}^{-1}, 30 \mathrm{~cm}^{2} \mathrm{~V}^{-1} \mathrm{~s}^{-1}$, and $25 \mathrm{~cm}^{2} \mathrm{~V}^{-1} \mathrm{~s}^{-1}$ for samples grown at $900^{\circ} \mathrm{C}, 860^{\circ} \mathrm{C}$, and $820^{\circ} \mathrm{C}$, respectively. The higher mobility for the sample grown at $900^{\circ} \mathrm{C}$ is consistent with a decrease in scattering events due to both lower dislocation density and $\mathrm{O}$ impurity concentration.

To explain our results, we consider $\mathrm{N}$-vacancies. As discussed above, early reports suggested Nvacancies as a possible cause of the background doping. This idea became overshadowed by the suggestion of $\mathrm{O}$ as the culprit for the $n$-type background. One major reason behind this was the unreasonably high formation energy of $\mathrm{N}$-vacancy. ${ }^{3}$

Since then, both calculations and electron irradiation measurements have shown that $\mathrm{N}$-vacancies for charged states that were previously not considered do indeed exist with reasonable formation energies, with donor levels in the range of $44 \mathrm{meV}$ to $70 \mathrm{meV}^{33,34}$

In Ref. 35, evaporation of $\mathrm{N}$ from the GaN growth front is demonstrated and discussed. The rate of creation of $\mathrm{N}$-vacancies increased with increasing substrate temperature. This is consistent with what we observed for our samples. Our conclusion is therefore that $\mathrm{N}$-vacancies are the probable cause of the observed background doping in our samples.

An illuminating next step would be direct observation of $\mathrm{N}$-vacancies by positron annihilation. 
Another interesting consideration for future experiments would be use of GaN templates, which have seen an increase in popularity as an alternative to sapphire or $\mathrm{SiC}$ substrates.

\section{ACKNOWLEDGEMENTS}

This work was supported by the Swedish Energy Agency.

\section{OPEN ACCESS}

This article is distributed under the terms of the Creative Commons Attribution 4.0 International License (http://creativecommons.org/licenses/by/4.0/), which permits unrestricted use, distribution, and reproduction in any medium, provided you give appropriate credit to the original author(s) and the source, provide a link to the Creative Commons license, and indicate if changes were made.

\section{REFERENCES}

1. M. Ilegems and H. Montgomery, J. Phys. Chem. Solids 34, 885 (1973).

2. B. Monemar, O. Lagerstedt, and H. Gislason, J. Appl. Phys. 51,625 (1980).

3. C.G. Van de Walle and J. Neugebauer, J. Appl. Phys. 95, 3851 (2004)

4. P. Perlin, T. Suski, H. Teisseyre, M. Leszczynski, I. Grzegory, J. Jun, S. Porowski, P. Bogusławski, J. Bernholc, and J. Chervin, Phys. Rev. Lett. 75, 296 (1995).

5. L. Li, M. Jurkovic, W. Wang, J. Van Hove, and P. Chow, Appl. Phys. Lett. 76, 1740 (2000).

6. S. Nakamura, N. Iwasa, M. Senoh, and T. Mukai, Jpn. J. Appl. Phys. 31, 1258 (1992).

7. Y. Zhang, Z.-H. Zhang, S.T. Tan, P.L. Hernandez-Martinez, B. Zhu, S. Lu, X.J. Kang, X.W. Sun, and H.V. Demir, Appl. Phys. Lett. 110, 033506 (2017).

8. G.R. Mutta, S. Carapezzi, A. Vilalta-Clemente, N.A. Kauffman, N. Grandjean, and A. Cavallini, Mater. Sci. Semicond. Proc. 55, 12 (2016).

9. E.C. Young, B.P. Yonkee, F. Wu, B.K. Saifaddin, D.A. Cohen, S.P. DenBaars, S. Nakamura, and J.S. Speck, J. Cryst. Growth 425, 389 (2015).

10. C. Skierbiszewski, Z. Wasilewski, I. Grzegory, and S. Porowski, J. Cryst. Growth 311, 1632 (2009).
11. A. Kuramata, K. Domen, R. Soejima, K. Horino, S.-I. Kubota, and T. Tanahashi, J. Cryst. Growth 189, 826 (1998).

12. A. Ping, Q. Chen, J. Yang, M.A. Khan, and I. Adesida, IEEE Electron Device Lett. 19, 54 (1998).

13. S. Strite, M. Lin, and H. Morkoc, Thin Solid Films 231, 197 (1993).

14. T. Tingberg, A. Larsson, and T. Ive, Phys. Status Solidi A 213, 2498 (2016).

15. O. Brandt, R. Muralidharan, P. Waltereit, A. Thamm, A. Trampert, H. Von Kiedrowski, and K. Ploog, Appl. Phys. Lett. 75, 4019 (1999)

16. S. King, C. Ronning, R. Davis, R. Busby, and R. Nemanich, J. Appl. Phys. 84, 6042 (1998).

17. L. He, Y. Moon, J. Xie, M. Muñoz, D. Johnstone, and H. Morkoç, Appl. Phys. Lett. 88, 071901 (2006).

18. C. Kruse, S. Einfeldt, T. Böttcher, D. Hommel, D. Rudloff, and J. Christen, Appl. Phys. Lett. 78, 3827 (2001).

19. E. Piquette, P. Bridger, R. Beach, T. McGill, in MRS Proceedings (1998), p. G3.77.

20. A. Corrion, F. Wu, and J. Speck, J. Appl. Phys. 112, 054903 (2012).

21. B. Heying, R. Averbeck, L. Chen, E. Haus, H. Riechert, and J. Speck, J. Appl. Phys. 88, 1855 (2000).

22. B. Heying, I. Smorchkova, C. Poblenz, C. Elsass, P. Fini, S. Den Baars, U. Mishra, and J. Speck, Appl. Phys. Lett. 77 , 2885 (2000).

23. B. Heying, E. Tarsa, C. Elsass, P. Fini, S. DenBaars, and J. Speck, J. Appl. Phys. 85, 6470 (1999).

24. A. Parkhomovsky, A. Dabiran, B. Benjaminsson, and P. Cohen, Appl. Phys. Lett. 78, 2315 (2001).

25. R. Chierchia, T. Böttcher, H. Heinke, S. Einfeldt, S. Figge, and D. Hommel, J. Appl. Phys. 93, 8918 (2003).

26. V. Ramachandran, A. Smith, R. Feenstra, and D. Greve, J. Vac. Sci. Technol. A 17, 1289 (1999).

27. N.G. Weimann, L.F. Eastman, D. Doppalapudi, H.M. Ng, and T.D. Moustakas, J. Appl. Phys. 83, 3656 (1998).

28. T.T. Mnatsakanov, M.E. Levinshtein, L.I. Pomortseva, S.N. Yurkov, G.S. Simin, and M.A. Khan, Solid-State Electron. 47, 111 (2003).

29. U.S.P.R. Karthik and P. Mallick, Nat. Sci. 3, 812 (2011)

30. S. Dhar and S. Ghosh, J. Appl. Phys. 86, 2668 (1999).

31. D. Meister, M. Böhm, M. Topf, W. Kriegseis, W. Burkhardt, I. Dirnstorfer, S. Rösel, B. Farangis, B. Meyer, and A. Hoffmann, J. Appl. Phys. 88, 1811 (2000).

32. A.F. Wright, J. Appl. Phys. 98, 103531 (2005).

33. D.C. Look, G.C. Farlow, P. Drevinsky, D. Bliss, and J. Sizelove, Appl. Phys. Lett. 83, 3525 (2003).

34. J. Buckeridge, C.R.A. Catlow, D. Scanlon, T. Keal, P. Sherwood, M. Miskufova, A. Walsh, S. Woodley, and A. Sokol, Phys. Rev. Lett. 114, 016405 (2015).

35. M. Ganchenkova and R.M. Nieminen, Phys. Rev. Lett. 96 , 196402 (2006) 